\title{
THE I-49 CONNECTOR: URBAN DEVELOPMENT ENHANCED THROUGH COLLABORATION AND INTERDISCIPLINARY SCHOLARSHIP
}

\author{
TOM SAMMONS ${ }^{1}$, KARI SMITH $^{1,3}$, KIWANA MCCLUNG ${ }^{1}$, ASHLIE LATIOLAIS $^{1} \&$ CATHRYN CORE $^{2}$ \\ ${ }^{1}$ School of Architecture and Design, University of Louisiana at Lafayette, USA \\ ${ }^{2}$ MESH Architects, USA \\ ${ }^{3} \mathrm{AECOM}, \mathrm{USA}$
}

ABSTRACT

The I-49 Connector project is a major highway development plan that arose due to the need for continuous access between an interstate route and a Federal-Aid highway system. The project is a part of a proposed North American Free Trade (NAFTA) highway that will span continuously from Winnipeg, Manitoba, Canada to New Orleans, Louisiana, United States. Currently, Interstate 49 transitions to surface streets at the Interstate 10 intersection in Lafayette, Louisiana and continues in this manner for several miles where the eastbound surface streets then transition into US Highway 90. Connecting Interstate 10 and Highway 90 into a continuous arterial will link two economically beneficial interstate routes, and concurrently provide citizens of southern Louisiana with a safe and effective route during emergency evacuations. Since the initial public hearings in 1992, the Community Design Workshop (CDW) within the School of Architecture and Design at the University of Louisiana at Lafayette has worked diligently to generate ideas to serve the project.

Keywords: urban planning, architectural education, public planning methodologies, highway, context sensitive solutions, collaboration.

\section{INTRODUCTION}

In 2015, the University of Louisiana at Lafayette Community Design Workshop (CDW) was contracted to work with the Louisiana Department of Transportation and Development (LaDOTD)/Lafayette Connector Partners (LCP) team to address the proposed I-49 Connector project in Lafayette, Louisiana. The CDW team was tasked with conducting a series of semester-long community planning and urban design workshops to address the I-49 Connector-related planning and design issues within study area levels I and II and prepare an urban design framework master plan for those areas in support of the project.

The CDW is a university-based planning team in the School of Architecture and Design at the University of Louisiana at Lafayette. The LaDOTD/LCP team is composed of transportation system officials; AECOM, a firm of over 87,000 employees, with offices in 150 countries, that specializes in infrastructure projects; and Stantec a firm of over 22,000 employees, with offices in seven countries, that specializes in engineering, consulting and professional design services.

There are many differences between professional planning teams and university-based planning teams, but a partnership between the two can be mutually beneficial. Professional engineers, consulting and project management teams rarely work on a single project. Large firms with many employees, those who are most likely to be hired to develop large-scale planning projects, must take on multiple projects simultaneously as a good business model - particularly offices that do public work projects, which are notorious for fits and starts depending upon the political climate. Consequently, time spent, and the number of people on a project is limited. Furthermore, expert teams hired to acquire large-scale planning projects are likely to be firms from other states or even countries. 
In contrast, university-based urban planning teams, such as the $\mathrm{CDW}$, rarely work on more than one project at a time due to university structures (i.e. project timelines that are determined by the length of a semester). They can typically operate outside of (to a degree) the capricious wills of government officials. They can dedicate a lot of people to a project continuously, although the timeframe may be shorter, 15 weeks (the length of a semester) or $1 \frac{1}{2}$ years (the length of a graduate students' education), compared to a planner in an office. University-based planning teams are most likely only capable of taking on one facet of the overall contract for large scale projects, such as the I-49 Connector project, but they can delve deeply into that contribution. Finally, university-based planning teams are most likely local and may contribute enormously to the projects teams' credibility from the perspective of community stakeholders.

\section{THE COMMUNITY DESIGN WORKSHOP}

The Community Design Workshop is one of six design research initiatives at the School of Architecture and Design at the University of Louisiana at Lafayette. Over the past twenty years, the CDW has produced over 100 projects that have focused on planning for small towns, regenerating neighbourhoods, participating in university master planning, designing linear parks along transportation networks, and restoring hurricane-devastated communities in southwest Louisiana.

\subsection{Approach}

The CDW's approach has four distinct methods for engaging the public. These include; 1) establishing transparent meetings, 2) establishing mobile sidewalk studios in the study area, 3) conducting public charrettes, and 4) establishing an office in the study area known as squatting. This collaboration places value on engaging the stakeholders and giving them a voice in the process. The CDW's approach organizes the different types of engagement for the intended audiences within varying time frames, different venues, and anticipated outcomes. The use of public meetings were borrowed from other venues. Mobile sidewalk studios were invented as a need arose for the public to be engaged in the process but in a less formal setting. Charrettes were modified to the appropriate skill sets of undergraduate and graduate architecture students. Squatting was adopted from previous architecture design practices made popular during the 1970s. Many of these approaches were established before CSS was adopted by the Federal Highway Administration.

\subsection{Public meetings}

The CDW team typically begins a project by holding a public meeting that provide opportunities to introduce the project process and goals to stakeholders and for the CDW team and stakeholders to meet. Public meetings are usually held in a venue within the stakeholder's neighbourhood, such as a church or community center, and they are often attended by residents, professionals, property owners, business owners, and city officials. Stakeholder diversity is useful at this juncture in the process because it allows the CDW team to think about a large number of perspectives and glean information necessary to the development of the project. The number of public meetings held is usually determined by the direction and input from the stakeholders. The public meeting primarily is identified as a kick-off event with numerous meetings that follow and culminating with the public final presentation. 


\subsection{Sidewalk studios}

The mobile sidewalk studio, the most informal and improvisational approach, is conducted in neighbourhoods and/or downtowns, and allows the CDW team to meet people on the street. CDW team members visually survey and record the context, conduct interviews and distribute questionnaires and comment cards. The informal venue, in the stakeholder's enclave, typically one-on-one, often results in more candid communication and CDW team members naturally develop a sense of the personal significance the project holds for stakeholders. Multiple sidewalk studios may occur throughout the project in response to the stakeholder's public input.

\subsection{Charrettes}

A useful method for conducting focused feedback sessions is the design charrette. Charrettes are short, intensive design sessions where stakeholder's ideas are expressed and then translated, by the CDW team, into design solutions that directly address the stakeholder's expressed needs. Like the public meeting, charrettes are usually held in a venue within the stakeholder's neighbourhood, recognizing that a resident will likely have a different perspective than a city official, for example, the CDW may create multiple charrettes aimed to address differing issues and /or to target different stakeholder groups. The goal of the charrette is to generate positive strategies for dealing with complex planning issues, create illustrative and evocative visualizations - such as vignettes or perspective drawings that are easily assessable to stakeholders, and to demonstrate to stakeholders that their ideas are heard and considered to be important by the CDW team.

\subsection{Squatting}

Long-term stakeholder interaction occurs by "squatting" in an office located in the project area, usually for the length of the project, thereby allowing the CDW team and all aspects of the design process to be available to stakeholders. The occupation of space in the project area promotes easy access to the CDW team on a day-to-day basis. While "on location", the CDW carries out a design studio, structured in the architecture program undergraduate and graduate-level curriculum. Space has been provided by city agencies, such as the Parks and Recreation or the Department of Transportation. The commitment to keep a studio in the project area creates, for CDW team members, a meaningful immersive experience of the context.

The CDW has determined that by using this variety of approaches and methods for its process and with its outreach efforts to engage stakeholders which an effective level of trust is built between the CDW team members and the stakeholders. This trust will ultimately result in the high-quality planning process and the production of design solutions.

\section{CONTEXT SENSITIVE SOLUTIONS}

The CDW has a long history with the I-49 Connector project. It first began working on this project in the early 1990's and has periodically worked on it in a series of urban design studios in the years 1999, 2003 and 2004 sponsored by the local Metropolitan Planning Organization. During this time span, the CDW employed its techniques of public engagement, visualization, and design processes including publications, exhibitions and the CDW's overall understanding of the connector project. In 2015, the LaDOTD/LCP team recognized the value and expertise that the CDW could contribute to the Context Sensitive Solutions (CSS) phase of the contract. 
Context Sensitive Solutions (CSS) is a collaborative and interdisciplinary design approach to planning and design. CSS is a relatively new process that evolved in the profession for the design of large transportation facilities [1]. The 1998 Transportation Equity Act for the 21st Century (TEA-21) through law PL 105-178, continues the initiatives of the Intermodal Surface Transportation Efficiency Act of 1991 (ISTEA) to provide safe, economically effective transportation while protecting communities and addressing environmental concerns [2].

\subsection{CSS methodology}

While there is consensus regarding the effectiveness of the CSS goals and principles, there is no defined methodology. Understanding how CSS principles can be effective to a project is subjective, place driven and requires envisioning engagement at a variety of scales. Prior to adopting the principles of CSS, the Federal Highway Administration (FHWA) had no mechanism, in the development of transportation solutions, to address the effects of highways on human and natural systems. In the absence of a CSS program, highways projects were "highly detrimental to the urban fabric; creating physical and psychological rifts that are (now) extremely difficult to bridge [3]" The adoption of a CSS program is a "180-degree transformation to earlier thinking of an engineering dominated practice." The FHWA now promotes the CSS program and initiatives to enhance effective public involvement, thorough assessment of impacts of proposed transportation solutions, and creative approaches to mitigation and enhancement [1]. The core CSS principles that apply to transportation processes, outcomes, and decision-making are:

1. Strive towards a shared stakeholder vision to provide a basis for decisions.

2. Demonstrate a comprehensive understanding of contexts.

3. Foster continuing communication and collaboration to achieve consensus.

4. Exercise flexibility and creativity to shape effective transportation solutions, while preserving and enhancing community and natural environments.

The presence of a "local champion" or facilitator of public engagement and the presence of clear political leadership are additional aspects that are important to the CSS process [4]. It is these four principles, however which embody the spirit of CSS, which is collaboration between, and inclusion of all affected parties.

\subsection{CSS and visualization}

The visualization of information and ideas has numerous benefits to the CSS process. Graphically representing ideas through vignettes and perspectives can assist stakeholders in creating a shared vision. In a 2010 paper on Public Involvement in Transportation Project Planning and Design, several case studies of past public planning projects reveal that visualization was a key component to articulating design visions and garnering community support [4]. Graphically representing information such as building typologies, codes, and urban morphology can assist the team in developing a contextual understanding. The CDW team was able to contribute to the LaDOTD/LCP teams' comprehensive understanding of the context through the production of two graphically-rich publications which analysed the organizational complexities of neighbourhoods directly affected by the proposed project. These publications have continued to serve as reference documents for all team members. Finally, graphically representing ideas and information though renderings, for example, complements spoken communication and may increase communication effectiveness. 


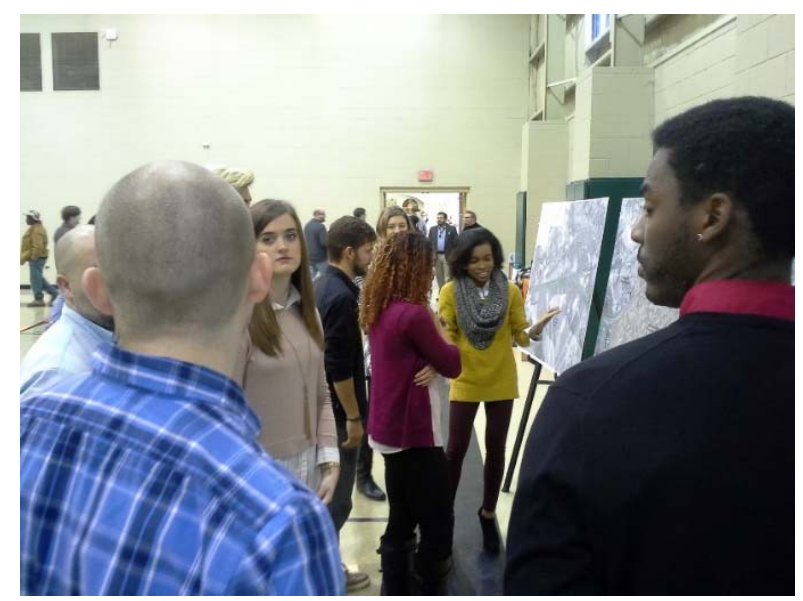

Figure 1: CDW participates in LCP public workshop. (Source: $C D W, 2016$.

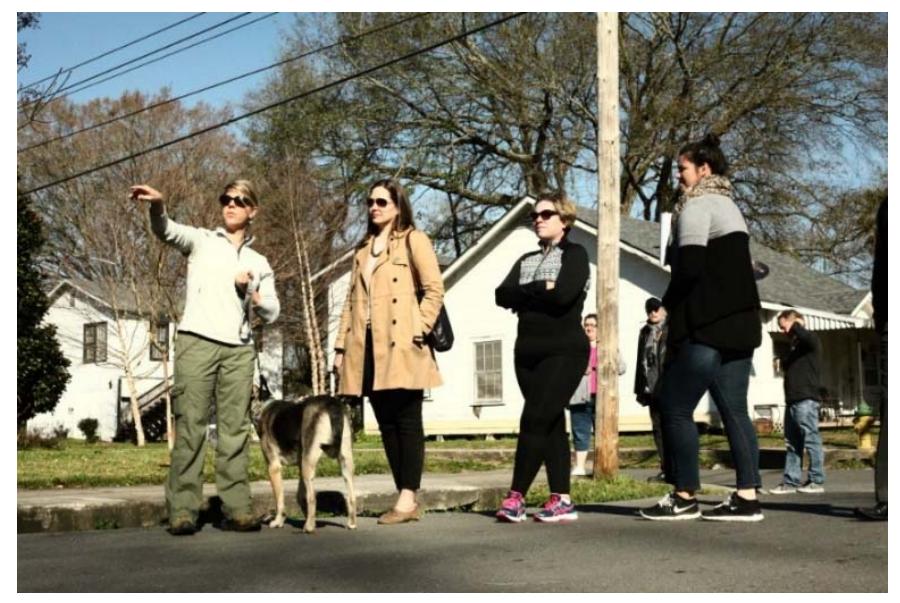

Figure 2: CDW and LCP conduct neighbourhood walkabouts. (Source: $C D W, 2016$.

Certain drawing types are efficacious realistic three-dimensional representations that allow the viewer to understand the proposed scale, materiality and space of a place. The CDW team has become adept in producing animations, which creates the illusion of a real world walk-through experience. Case studies on transit-oriented development projects employing CSS planning methods cite visualization as an effective method for communication design ideas and clarifying the goals of the project. Visualizations also give the intentions of the project increased public credibility. Projects employing the CSS process in preceding planning efforts have later reported increased levels of clarity between stakeholders in terms of desired outcome and overall direction.

An important principle to the CSS program is flexibility and creativity in shaping design solutions. Now in the third year, over 50 students have persistently interrogated the project, through multiple methods, offering up a wide variety of solutions to various alignments. In each of these examples, students sought to preserve and enhance human and natural systems. 
Many of these design solutions have been shared in exhibitions and publications intended to facilitate and extend dialogue amongst stakeholders.

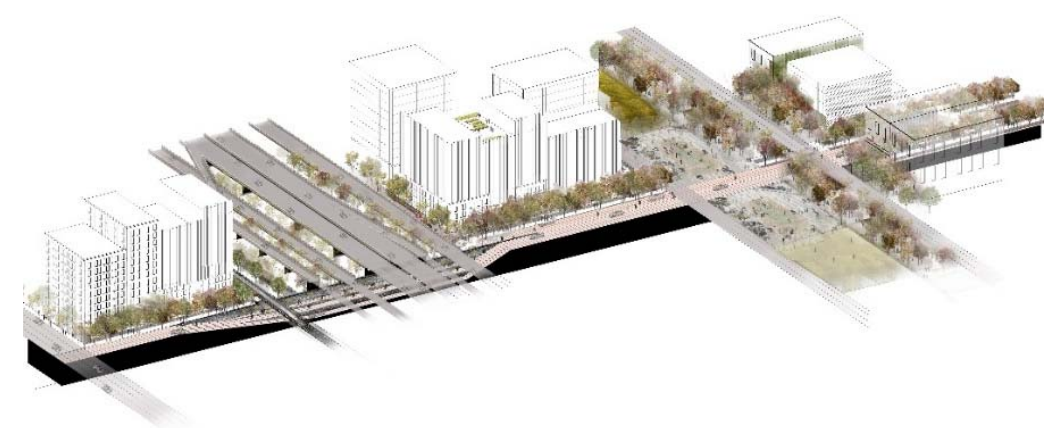

Figure 3: Axon of I-49 urban planning solution. (Source: CDW Redbook, 2017.)

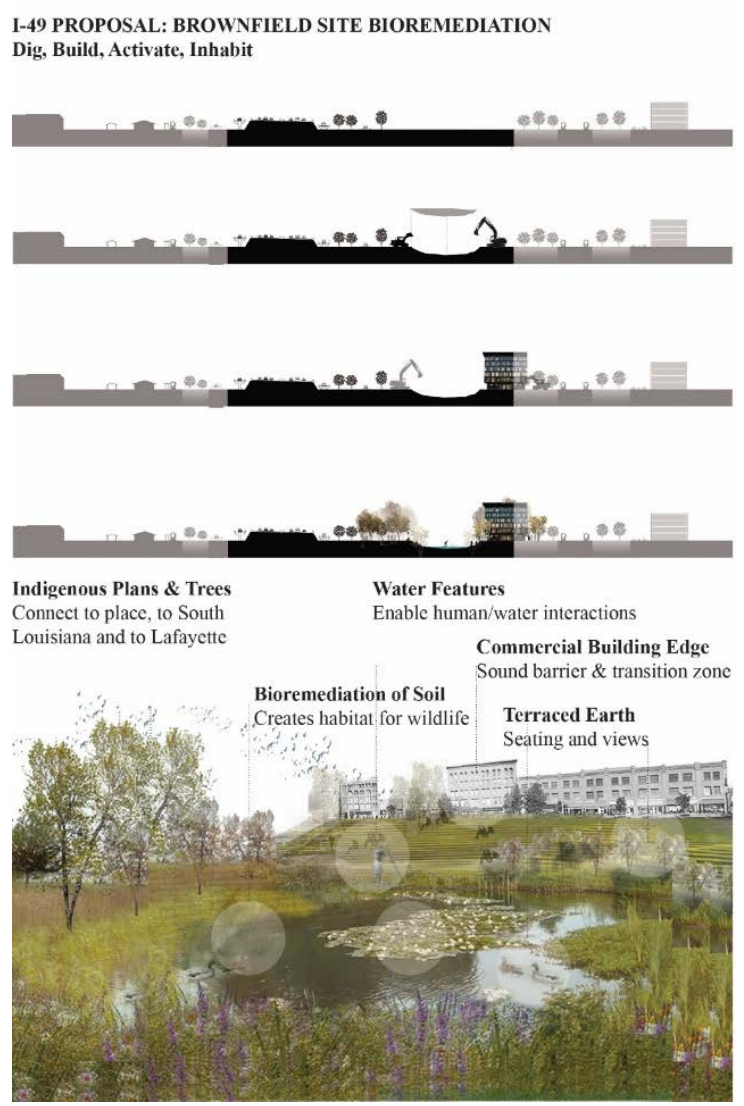

Figure 4: Visualization of environmental remediation proposals. (Source: CDW Redbook, Smith, 2017.) 


\subsection{Outreach}

Exhibitions and publications are just two mechanisms the CDW team utilizes as part of its outreach effort. Team members have attended community planning and urban design workshops organized by the LaDOTD/LCP team. CDW team members assisted the LaDOTD/LCP team with analytics and ensured that public comment was processed quickly and made available in the project library on the I-49 Connector website. The I-49 Connector website is an official source of information that archives progress on the I-49 Connector project. It also serves as a supplemental tool to allow stakeholders a means of providing public comment.

When the CSS process for the I-49 Lafayette Connector began in 2015, community outreach, discussion and debate were focused primarily on one issue: the CSS design feature areas and elements of the corridor. After speaking with hundreds of community members and agency stakeholders in individual meetings and public forums, however, it became apparent that the next step to advance the I-49 Lafayette Connector was much more complex. It is not rare to see sudden changes in understanding of context when community involvement is introduced into the CSS process. In the paper Understanding Minority Residents' Perceptions of Neighbourhood Risks and Environmental Justice: New Modalities, Findings and Policy Implications, the authors assert that the members of communities affected by large-scale planning projects “... experience environmental injury in ways that are deeper and more complex than this simple notion of Risk.". Indeed, several community groups voiced concerns over both the environmental and contextual issues related to the I-49 connector.

\section{PROJECT READJUSTMENT}

When the project was restarted in 2015, it had been over twelve years since the completion of the FEIS/ROD and, during this time span, the community underwent significant changes. Community input indicated that the 2002 selected alternative was no longer the preferred concept for the I-49 Connector, and the community wanted to see various design modifications to that alternative to make it fit better within the context of Lafayette, as well as make it more acceptable to the community.

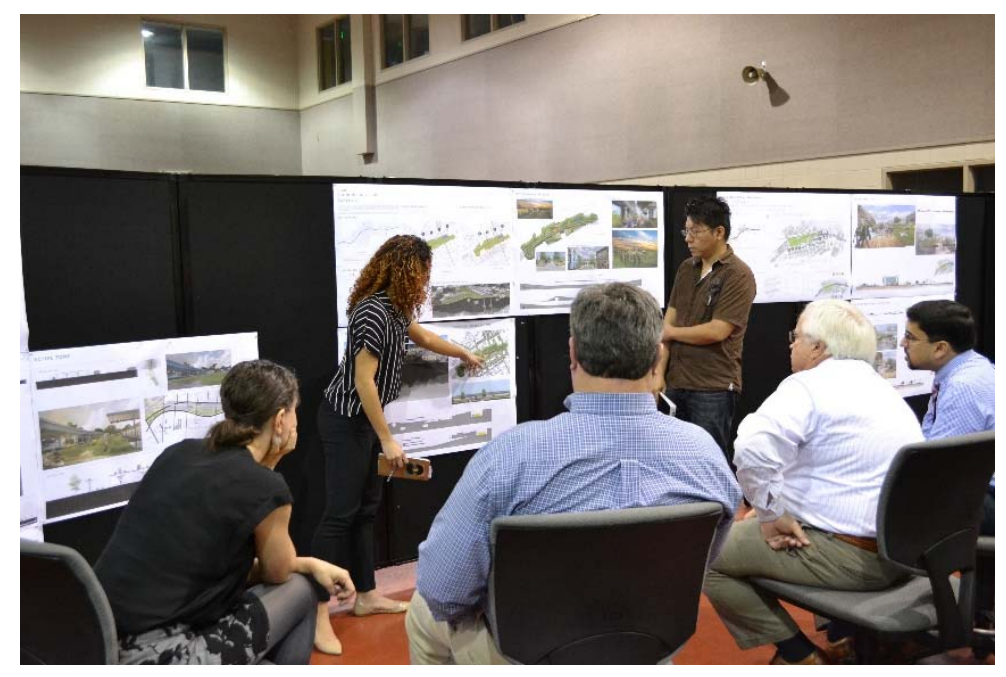

Figure 5: CDW presents design options to LCP collaborators. (Source: $C D W, 2016$. 
As a result, the FHWA and DOTD decided to initiate a Supplemental Environmental Impact Statement (SEIS) phase, including a Concept Refinement Process (CRP), to identify and evaluate the various alignment modifications to the original 2003 Record of Decision Selected Alternative based on community and stakeholder agency input, and document the related environmental impacts in an SEIS document.

\subsection{Redefining Initiatives}

The urban design and master plans were generated primarily in the graduate-level studio. Studios at the School of Architecture and Design at the University of Louisiana at Lafayette are intensely committed to community outreach are place-based and topic-based studios. Specialized design research initiatives in the Master of Architecture Program focus on projects that make unique contributions to the University's scholarship, community engagement, service, and teaching. These design research initiatives are aimed at providing professional services to our communities and society. Engaging students in the I-49 Connector project has actualized a number of learning objectives concurrently fulfilling accreditation criteria. Students:

1. Develop a working knowledge of and appreciation for related disciplines with whom they may interact with as professional.

2. Develop and understanding of how to conduct themselves in a professional manner (i.e. time management, collaborative relationships, accountability, etc.).

3. Develop an understanding of stakeholder roles in the process.

4. Develop investigative and integrated evaluation and decision-making skills.

5. Develop an understanding of codes and regulations that govern the project.

6. Develop urban planning design skills.

\subsection{Academic challenges}

The conflict between an educational environment that is contracted to perform specific tasks brings into focus ethical challenges, such as the I-49 Connector project, which compensates faculty and advances faculty research, into a for-credit structure. As Ursula Emery-McClure cautions, "while it is common for architectural studios to be underwritten by grant money as an extension of faculty-based research agendas, we must be vigilant that student-learning objectives are primary, that faculty researchers are forthright with their students about the relationship between research and coursework, that there is equitable treatment of students, and that students are credited with their contribution to the research". The frequency in which this situation presents itself and potential for ethical slippage grows as Dodds and Erdman note because, "the focus on design-as-research is propelled in academe by institutional directives largely in search of external funding sources".

As external (to learning objectives) drivers, such as university strategic imperatives for research apply pressure to faculty to bring in funded projects, the CDW offers a model for how to structure studios underwritten by contracts. When projects, such as the I-49 Connector project are structured in a studio class, students are made aware - from the first day of class that they are collaborators on a grant. Additionally, the students are made aware of the team members and their hierarchal relationship between the DOTD, the consultants (STANTEC and AECOM) and the studio. Student learning outcomes and the value of the project to fulfil these outcomes is also communicated. Serving as academic and project leaders, the faculty 
place a high value on transparency - that is, to share with them the underlying reasons for why we are asking them to do the work that they do. Work conducted for credit is experimental, provocative and explorative. This work is useful to the LaDOTD/LCP team because it generates alternative ways of thinking about the issues of the project. The work can be more visionary and take greater risks because it does not go out into the public realm. However, when the project necessitates deliverables that are more closely aligned to the political, engineering, and situational realities of the project, the work is given to CDW student team members who are paid interns or graduate research assistants. As collaborators responsible for professional products, the students are paid for their time either hourly or compensated through tuition waivers and monthly stipends. For credit and compensated student contributors are recognized, by name and role, in all exhibition and publication materials. To date, the most recent I-49 Connector project contract has supported four interns and one graduate research assistant.

\section{CONCLUSION}

The partnership that exists between the LaDOTD/LCP team and the CDW team on the I-49 Connector project illustrates that the partnership this type of association can be mutually beneficial and that the CSS process can be significantly enhanced when professional teams partner with university-based planning teams. The partnership also elevates the quality of education offered to students in university programs.

The I-49 Connector project has enabled faculty researchers and students to engage and serve their community and delve into the social, cultural, and political issues of large-scale planning projects. CDW team members gleaned substantial professional design experience through interdisciplinary collaboration and engaging in the CSS process. The CDW's team involvement with the contract-funded internships and graduate research assistantships. It has provided an exciting real-world learning opportunity for undergraduate and graduate-level students. Finally, the CDW team has generated urban design framework master plans alternatives that have stimulated robust discussions among stakeholders and decision makers.

\section{ACKNOWLEDGMENTS}

We would like to acknowledge the LaDOTD/LCP team for choosing to partner with the CDW team for the Context Sensitive Solutions phase of the I-49 Connector project. In particular we would like to express our deep gratitude to John McNamara, Jeffrey Grob, Vijayant Rajvanshi, and Sara Malmkvist for the many times that they served as critics in the studio, offering insight at critical moments in the CDW team's design process.

We would like to acknowledge the talent, dedication, and professionalism of the 58 graduate and 23 undergraduate students on the CDW team who contributed to the I-49 Connector project through research, analysis and design - students who believed that "design really can make a difference" and worked to give a voice and vision to Lafayette community stakeholders. In particular, we would like to acknowledge the extraordinary work of graduate students Cathryn Core and Katie LeLeaux for their editorial work on three CDW publications in support of the I-49 Connector project.

We would like to acknowledge current and past CDW team faculty contributors including: Hector LaSala, Robert McKinney, Brian Powell, and Jean Edwards for their persistent commitment to the project. We would also like to acknowledge our unofficial CDW team member, Susan Cook, for all of her administrative, editorial, and moral support.

Finally, we would like to acknowledge our colleagues and administrators in the School of Architecture and Design, the College of the Arts, and the University of Louisiana at Lafayette for their continued support of educating students through community engagement. 


\section{REFERENCES}

[1] United States Department of Transportation, Federal Highway Administration, Context Sensitive Solutions. Online. https://www.fhwa.dot.gov/planning/css/. Accessed on: 20 Mar. 2017.

[2] United States Department of Transportation, Federal Highway Administration, The Transportation Equity Act for the 21st Century (TEA-21) - A Summary. Washington, 1998.

[3] Semuels, A., The Atlantic, Online. www.theatlantic.com/business/archive/2015/11/ highways-destroyed-americas-cities/417789/. Accessed on: 20 Mar. 2017.

[4] Slotterback, C.S., Public Involvement in Transportation Project Planning and Design. Journal of Architectural and Planning Research, 27(2), pp. 144-162, 2010.

[5] Lejano, R.P. \& Stokols, D., Understanding Minority Residents' Perceptions of Neighborhood Risks and Environmental Justice: New Modalities, Findings and Policy Implications. Journal of Architectural and Planning Research, 27(2), pp. 107-123, 2010.

[6] Emery-McClure, U., The Good, the Bad, and the Ugly. Journal of Architectural Education, 61(1), pp. 73-75, 2007.

[7] Dodds, G. \& Erdman, J., Introduction. Journal of Architectural Education, 61(1), p. 4, 2007.

[8] U.S. Environmental Protection Agency, Office of Solid Wastes, SW-846, "www.epa.gov," Online. www.epa.gov/epaoswer/hazwastes/test/main.htm. Accessed on: 23 Jun. 2015.

[9] Community Design Workshop (CDW), Preface. I-49 Connector Project Volume I, Lafayette, CDW: LA, p. 4, 2017. 